\title{
La Mercadotecnia de las Letras: Libros, Librerías y Consumidores
}

\section{The Marketing of Letters: Books, Bookstores and Consumers}

\author{
ORTÍZ-ALVARADO, Francisco Jesús $\dagger^{*} *$ \& VARGAS-NERI, Juan Fernando \\ Universidad Autónoma de San Luis Potosí, Facultad de Ciencias de la Comunicación \\ ID $1^{\text {er }}$ Autor: Francisco Jesús, Ortíz-Alvarado / ORC ID: 0000-0002-4547-8361, Researcher ID Thomson: S-7731-2018, \\ CVU CONACYT ID: 947400
}

ID $1^{\text {er }}$ Coautor: Juan Fernando, Vargas-Neri / ORC ID: 0000-0002-4410-2688, Researcher ID Thomson: S-7739-2018, CVU CONACYT ID: 947404

DOI: $10.35429 / J P D L .2019 .14 .5 .20 .31$

Recibido 29 de Enero, 2019; Aceptado 30 Marzo, 2019

\section{Resumen}

La Mercadotecnia es un conjunto de técnicas que constituyen todo un proceso de comercialización. La industria editorial mexicana no es la excepción. Aunque tiende a asociarse una estrategia mercadológica al lanzamiento de un cereal o la renta de apartamentos en un destino turístico, los libros también construyen su perfil de negocio como productos, si bien culturales, pero igual son identificados como elementos propios de los intercambios materiales, insertos en la cadena de producción de bienes de consumo y están sujetos a las mismas leyes de los mercados. La investigación fue de alcance exploratorio y de tipo no experimental y diseño transeccional. La muestra fue de 250 sujetos con respecto al total de pobladores de la capital potosina: nivel de confianza de $95 \%$ y un intervalo de 6.2 , elegidas de forma aleatoria y que ingresaran a la librería objeto de estudio, donde se aplicó la técnica de encuesta con catorce cuestionamientos cerrados y dos abiertos. Este artículo busca identificar, a partir de las cinco variables mercadológicas fundamentales, qué mecanismos determinan la compra/venta de estos artículos, con el objetivo de generar conocimiento en Comunicación de negocios en la capital del Estado en cuanto al mercado editorial.

Mercadotecnia, Industria editorial, Consumidores de libros

\begin{abstract}
Marketing is a set of techniques that constitute a whole marketing process. The Mexican publishing industry is no exception. Although a marketing strategy tends to be associated with the launch of a cereal or the rental of apartments in a tourist destination, the books also build their business profile as products, although cultural, but they are still identified as elements of the material exchanges, inserts in the chain of production of consumer goods and are subject to the same laws of the markets. The research was of exploratory and nonexperimental type and transectional design. The sample was 250 subjects with respect to the total population of the capital: confidence level of $95 \%$ and a range of 6.2 , chosen at random and entering the library under study, where the survey technique was applied with fourteen questions closed and two open. This article seeks to identify, from the five fundamental market variables, which mechanisms determine the purchase / sale of these articles, with the aim of generating knowledge in business communication in the state capital regarding the publishing market.
\end{abstract}

Marketing, Publishing industry, Consumers of books

Citación: ORTÍZ-ALVARADO, Francisco Jesús \& VARGAS-NERI, Juan Fernando. La Mercadotecnia de las Letras: Libros, Librerías y Consumidores. Revista de Filosofía y Cotidianidad. 2019, 5-14: 20-31

\footnotetext{
* Correspondencia del Autor (juanf@ cunorte.udg.mx)

$\dagger$ Investigador contribuyendo como primer Autor.
} 


\section{Introducción}

Si bien la disciplina de la Mercadotecnia cuenta con infinitas aproximaciones teóricas tanto para su definición como a sus formas de implementación, todas éstas confluyen en el hecho de que es un conglomerado siempre cambiante e innovador de técnicas, variables y mecanismos de acción, que buscan insertar dentro de los procesos de generación/adquisición de compra y experiencia a toda suerte de satisfactores, que se distinguen por una permanente y belicista competencia por apoderarse del gusto de los individuos que pertenecen a un mercado específico y actualmente globalizado, con el fin de establecerse temporal y posteriormente de manera definitiva, en las predilecciones por rubros de compra de sus públicos meta.

Tanto la industria como el mercado editorial mexicano e internacional - en español forman parte de esta logística de comercialización, aunque sus productos sean diferentes pues son catalogados como bienes culturales y en apariencia estén distanciados por su naturaleza propia de contenidos e intenciones creadoras - son desde su génesis, bienes de consumo apreciados por un numeroso y bien definido sector poblacional, que ya sea por sus aspiraciones artísticas, de status, entretenimiento o requerimientos académicos o profesionalizantes, han ido conformando a lo largo de siglos, un cuerpo de consumidores, seguidores o coleccionistas - por mencionar solamente algunas de las especificaciones en que pueden a su vez integrarse los sujetos de este grupo objetivo - que dentro de sus preferencias y hábitos de compra, ubican a los libros en un espacio dentro de su escala de adquisiciones de manera estable y constante.

Si bien por equivocada o intencional asociación mercadológica, los libros han sido catalogados como artículos suntuarios por el imaginario de la población: tal vez debido a sus precios, a sus selectas redes de distribución, por ser identificados como vehículos de la intelectualidad clásica e imperante o por la exclusividad de las plazas donde se exhiben para su venta. Sin embargo en la actualidad, el mercado editorial mexicano ha ido diversificando sus estrategias de Mercadotecnia, con el fin de modificar estas percepciones generalizadas para darles una visión renovada de modernidad.
Así como de inclusión socioeconómica y de contenidos, apegándose a las tendencias globales de consumo y diversificándose también en materia de segmentos poblacionales, explorando nuevos espacios de venta como los puestos/quioscos de periódicos y revistas, además de una efectiva adecuación y modernización de sus lugares tradicionales de venta - las librerías - para redefinirlas como lugares más relajados, amigables y atractivos para el grueso de la población, además de permitir que escritores de una diversidad inusitada sean ofertados a los consumidores así como, probar nuevos formatos como el electrónico, incrementar sus ventas en la modalidad en línea con entregas a domicilio o invertir en ferias, giras de autores, presentaciones de libros en fotos culturales $y$ académicos o estimular la creación literaria por medio de convocatorias abiertas para premios, becas o publicaciones a quienes de ellas participen. Este artículo tiene como intención, no sólo identificar y generar conocimiento acerca de los cinco mecanismos fundamentales del proceso de comercialización aplicado a los libros como productos, sino, asimismo, dilucidar la esencia de algunas prácticas mercadológicas y sus implicaciones y consecuencias en materia de consumo.

\section{Marco Teórico}

Por definición y naturaleza, la actividad mercadológica, a través del juego estratégico de sus variables constitutivas - abordadas posteriormente en este mismo documento bajo la visión de Pearson (2014, p. 3) - son ejercicios expresivos con intenciones comunicativas por excelencia. La conceptualización y la puesta en escena de un proceso integral de comercialización, es una actividad propia del campo disciplinar de la Comunicación: las expresiones en general tienen valor en un grupo humano determinado, por las asociaciones que los sujetos les asignan como consecuencia del entramado socio/cultural que han construido $\mathrm{y}$ las evoluciones que éste va presentando en el tiempo. Por lo tanto, toda expresión necesariamente lleva relacionada una intención comunicativa, no existe una expresión que no busque transmitir una idea, crear una interacción con un receptor, transmitir una información o crear/alimentar un imaginario social. Asimismo, la presencia y uso de medios de comunicación; el empleo diversificado del lenguaje; las técnicas y sus narrativas audiovisuales y fotográficas. 
La generación de contenidos de acuerdo con perfiles con intenciones de persuasión, intercambio y negociación, así como la práctica de modelos comunicativos que definen $y$ plantean formatos innovadores para la relación entre los sujetos, entre otras aproximaciones al fenómeno del consumo, enriquecen y consolidan esta reflexión.

De acuerdo a las aportaciones de Van Riel (2003) el ejercicio expresivo dentro/fuera de toda clase de organizaciones, adopta formas diversas en tres grandes áreas de acción: la denominada Comunicación de Dirección, enfocada en vincular a todos los miembros del cuerpo de trabajo e integrarlos para lograr la agenda de actividades, cumplir metas y objetivos, compartir los idearios y filosofía y que en términos generales, lleven a todo el grupo a buen término a través del conocimiento, e implementación de diferentes responsabilidades; la Comunicación Organizativa es la que "cubre las relaciones con las administraciones públicas...con los inversores, la comunicación con el mercado de trabajo, la publicidad corporativa, la comunicación ambiental, y la comunicación interna" y la Comunicación de Marketing es la que se emplea "como término general para cubrir la publicidad, las promociones de ventas, el marketing directo, el patrocinio, las ventas personales y otros elementos (de comunicación)" dentro de la mezcla mercadológica o de las variables relacionadas con esta actividad dentro del proceso de comercialización propio de las actividades productivas de una empresa.

En la teoría mercadológica y siguiendo a Lambin en Cardozo, la actividad de la Comunicación se define como aquel “...conjunto de señales emitidas por la empresa a sus diferentes públicos, es decir, hacia clientes, distribuidores, proveedores, accionistas, poderes públicos y también frente a su propio personal" (2007). La estrategia comunicativa en Mercadotecnia de una casa editorial, orientada a los consumidores de cierto perfil, es igual de importante en el conjunto de negocios, que la que se enfoca a las librerías que están colocando los volúmenes en el estante de novedades del mes o a sus colaboradores que organizan una gira de firmas con la autora por el sur de México.
Schiffman y Lazar también en Cardozo (2007) entienden a la variable del ejercicio comunicativo como aquella “...transmisión verbal y no verbal de información entre un transmisor y un receptor; transmisión de información entre emisor y receptor que debe hacerse por medio de una señal de algún tipo enviada a través de un canal de algún tipo".

Aunque la denominación oficial y definitiva de la disciplina mercadológica se remonta al año de 1450 en Europa a partir de la invención de la imprenta de acuerdo con Cortez (2016) el proceso de conceptualización, ingeniería y comercialización de productos y servicios ha estado presente desde el primitivo ejercicio del truque. El valor intrínseco y extrínseco de los objetos que rodean a la especie humana, es el detonante inicial de toda una cadena de consumo que responde a las esferas de las necesidades y de los deseos personales y colectivos.

La oferta, la demanda, la apariencia de los bienes a intercambiar, la importancia de su presencia en las vidas de los sujetos, las propuestas de valor, las implicaciones socio/culturales de los mismos, por mencionar algunos mecanismos de acción para la decisión de apropiarse de ciertos elementos considerados útiles (en cualquiera de las acepciones del término) fueron y continúan siendo las fuerzas que, tras bambalinas, articulan las prácticas de mercadeo básico en el escenario del consumo.

De las fundamentales redes y reglas del truque como génesis de la Mercadotecnia actual, deviene la compra/venta como un elemento de la configuración de la economía en las primeras civilizaciones, en donde además de solucionar las carencias básicas de alimento o vestido de los grupos humanos, comienzan a producirse, por parte de quienes se dedicaban a la floreciente industria de la producción, distribución y/o venta de mercancías, la detección de ciertos bienes que giraban en una esfera diferente del consumo tradicional y que respondían además a requerimientos en términos de deseos expresados en características específicas, que comenzaron a establecer las hoy denominadas tendencias de ciertos mercados, en donde los componentes estéticos, religiosos, de género, de clase, eran demandados cada vez con mayor intensidad. 
Los bienes de consumo además de ser destinados a la satisfacción biológica de las necesidades se convirtieron en símbolos de poder. El proceso de comercialización ya no se enfocaba sólo en la frescura de los alimentos o en el envase más duradero de los vinos, sino además en su unicidad, la moda, las líneas del diseño y fabricación, el color, su exótica procedencia o la exclusividad. Las marcas aparecieron como huellas físicas o sellos grabados en los materiales de los fabricantes o distribuidores, anunciando el nombre o emblema de los productores, garantizando una personalización, especialización o distinción por encima de aquellos que eran del consumo generalizado y que carecían de esa señal de origen o manufactura.

La diferencia fundamental entre estas circunstancias y la práctica actual mercadológica, es la innovación y complejidad de los instrumentos tecnológicos en el seno de la vida social globalizada, pero en sustancia, los procesos de comercialización continúan siendo muy similares. Todo proceso de comercialización para un bien encuentra su origen en el terreno de las necesidades y los deseos humanos y además en la articulación que guardan con los productos y servicios que se presentan en los escenarios de negocio para su consumo.

A partir de las investigaciones y el consecuente desarrollo teórico relacionado con el ámbito de los requerimientos humanos, por naturaleza y de acuerdo a Maslow en Sergueyevna y Mosher (2013) existen cinco grandes ámbitos en donde quedan identificadas todas las necesidades que un sujeto manifiesta a lo largo tanto de su vida, como de su desarrollo humano y que fueron estructuradas para su comprensión en el formato ilustrativo de una pirámide, cuya base representa las más fundamentales y conforme se van satisfaciendo se busca cumplimentar con las siguientes, fluyendo hacia arriba hasta las más complejas:

a. Fisiológicas: alimento, sexo, descanso.

b. Seguridad: en el empleo, integridad física, moral.

c. Afiliación: amistad, afecto, intimidad sexual

d. Reconocimiento: confianza, respeto, éxito.

e. Auto/Realización: incluye a la creatividad, espontaneidad, resolución de problemas entre otras.
La delimitación teórica de las necesidades y la territorialidad de consumo en cuanto al tema de los deseos ha ido perfeccionándose e implementándose cada vez con una precisión casi quirúrgica, en cuanto a la segmentación de mercados, sin embargo, la realización en sentido ascendente y escalonado no es siempre lineal, sino que es de especial trascendencia, en especial para la naturaleza de esta investigación, aclarar que los individuos eligen cuales necesidades llenar y el orden en que serán cumplimentadas de acuerdo a su jerarquía personal o colectiva de valores.

Puede ser que un ama de casa, suspensa temporalmente la saciedad del hambre (fisiológicas) por inscribirse a un grupo de ayuda (afiliación) que la ayude a superar sus problemas de control del apetito (auto/reconocimiento) para perder peso de manera significativa (resolución de problemas). Los mercadólogos pueden tratar de encauzar la toma de decisiones en cuanto a los procedimientos que en lo particular o grupal siguen los seres humanos para la satisfacción de sus diferentes escalas de necesidades, pero su influencia si bien es significativa jamás es determinante, debido a la formación del sujeto, su contexto e imaginario socio/cultural, su nivel de ingresos o los diferentes elementos que componen al proceso de comercialización: es un juego de variables que deben articularse de la manera más estratégica posible para que el fenómeno del consumo se active y concretice.

El afirmar que un segmento compra pan porque desea/necesita/puede comerlo, resulta poco profesional y alejado de la rigurosidad de todo ejercicio auténtico del científico social. Los seres humanos no buscan idénticos satisfactores para saciar la misma necesidad.

De acuerdo con Kotler y Armstrong en Stanton, Etzel y Walker (2004) las necesidades son "un estado de carencia percibida e incluyen: necesidades físicas básicas de alimentos, ropa, calor y seguridad; necesidades sociales de pertenencia y afecto, y necesidades individuales de conocimiento y autoexpresión. Estas necesidades son un componente básico del ser humano, no la inventaron los mercadólogos" quienes deben contar con la visión y pericia de saber identificar la circunstancia y naturaleza en que éstas aparecen y se van manifestando, para trabajar con ellas en su proceso de satisfacción vía elementos de consumo. 
Resulta esclarecedor y cientificista asegurar que las necesidades, en ninguna de sus modalidades, son creadas por quienes se desempeñan profesionalmente dentro del terreno mercadológico o publicitario; pertenecen y competen a la naturaleza/condición humana y a su vastedad de representaciones, condicionamientos o mecanismos de expresión social, biológica y cultural.

Cuando las necesidades son estimuladas mercadológicamente, se convierte en motivos para la compra: puede ser que en un horario vespertino específico, un segmento de mercado tenga altas probabilidades de presentar la necesidad de alimento, por lo que un comercial en redes sociales de un restaurante de sushi o una promoción impresa para descuento de una pizzería, activen la intención de adquirirlos para cumplir con el requerimiento corporal. Los deseos en consecuencia serían las asociaciones, identificaciones o encauzamientos que los mercadólogos establecen entre los consumidores o usuarios, sus diversas necesidades y los productos o servicios existentes.

En la lógica de Santesmases, Sánchez y Valderrey (2014) los deseos serían necesidades dirigidas a objetos de consumo específicos que podrían satisfacerlas. La Mercadotecnia de acuerdo con Kotler en Santesmases, Sánchez, Pintado y Merino. (2013) es "un proceso social y administrativo mediante el cual, grupos e individuos obtienen lo que necesitan y desean a través de generar, ofrecer e intercambiar productos de valor con sus semejantes" y es partir de este concepto, que Thompson (2006) elabora un modelo de Análisis Estructural, con la finalidad de profundizar en las complejidades teórico/prácticas tanto del término como de sus implicaciones y alcances en el ejercicio de los negocios.

Sería prudente en este punto afirmar que si bien los libros son elementos que no cumplen estrictamente con el requerimiento biológico del rango de las necesidades, sí son satisfactores dentro del rubro de los deseos, ya identificados como tales y que no escapan a la lógica mercadológica que se está abordando a lo largo de este material. De acuerdo con el autor, pueden identificarse nueve grandes áreas de reflexión:
1.- La Mercadotecnia es un proceso social y administrativo: en los intercambios interactúan personas con sus consecuentes manifestaciones en las modalidades de demandas, necesidades y deseos, los cuales según Kotler y Armstrong (2006, p. 5) son el punto de partida de la disciplina; su componente administrativo se localiza en la práctica que se hace de los elementos fundamentales planeación, organización, dirección, implementación, control - elementos que otorgan además un amplio sentido de orden al proceso de comercialización - motivos por lo que resulta prudente afirmar que todo proceso de comercialización es:

a. Realizado por y para seres humanos, afirmación que permite no deshumanizar ninguno de los componentes mercadológicos.

b. Si bien el ejercicio de la Mercadotecnia es una disciplina cambiante e innovadora, que se adecúa a los cambios socio/culturales de los grupos humanos, su accionar debe ser siempre administrado, para efectos de incrementar las probabilidades de éxito tanto de una empresa como de sus productos o servicios en un mercado determinado.

2.- La Mercadotecnia promueve el intercambio de productos/servicios de valor con sus semejantes: entendiéndose como el acto por el cual alguien obtiene algo (bien) entregando alguna cosa a cambio (dinero); según Kotler en García (2014, p. 152) para que esto suceda deben ocurrir cinco condiciones:
a. Que existan al menos dos partes.
b. Que cada parte posea algo que pueda tener valor para la otra parte.
c. Que cada parte sea capaz de comunicarse y hacer entrega.
d. Que cada parte tenga libertad para aceptar o rechazar la oferta.
e. Que cada parte considere que es apropiado o deseable negociar con la otra parte.


3.- La Mercadotecnia es una función de la empresa: además de las diversas áreas en las que se compone y desglosa un corporativo, el proceso de comercialización es una función igual de relevante que las que se desempeñan en otros departamentos y comprende gran cantidad de actividades con sus propios objetivos, los cuales, a su vez, permiten cumplir los generales de la agrupación comercial y de negocios. Consecuentemente, un enfoque mercadológico empresarial estratégico, incrementa las probabilidades de éxito en cuanto al cumplimiento no sólo de los objetivos/metas que se hayan planteado, sino que puede permitir que esos logros sean aún más fructíferos y duraderos.

4.- La Mercadotecnia está orientada a la identificación y satisfacción de necesidades (biología) y están relacionadas con los satisfactores básicos y los deseos (social) con los específicos; ambos deben ser identificados y satisfechos a través del diseño/creación de bienes acordes al requerimiento y al universo del mercado meta a cambio de una utilidad o beneficio.

5.- La Mercadotecnia permite evaluar la capacidad productiva de la empresa: a través de esta disciplina y a partir de la evaluación de necesidades/deseos de los consumidores y de los bienes de consumo que se generan, se puede obtener un referente de la productividad en sus tres vertientes: calidad, máximos rangos de producción y puntos de equilibrio.

6.- La Mercadotecnia utiliza un sistema total de actividades comerciales: que interactúan y actúan entre sí para cumplir los objetivos de negocio de la empresa en un periodo específico.

7.- La Mercadotecnia debe cumplir las metas de la empresa para mantenerla en vigencia: la agenda de actividades mercadológicas debe tener sinergia con todas las áreas de una organización, ya que es relevante no solamente cumplir metas de negocio, sino que, a través del logro de éstas, propiciar solidez, desarrollo, permanencia y crecimiento de todo el sistema.

8.- La Mercadotecnia se encarga de las relaciones con los clientes en beneficio de la organización: las cuales deben ser siempre sanas, satisfactorias, duraderas y permanentes, en especial en los escenarios actuales.
9.- La Mercadotecnia es un instrumento para competir con otras empresas: de acuerdo con Ries y Trout (2006, p. 109) cada organización busca conquistar posiciones, ventas, preferencias entre un segmento de mercado y esta disciplina es una herramienta para lograrlo, pues no solamente se lucha por disminuir costos de producción o incrementar la capacitación del personal para crear una plataforma estratégica de desempeño, sino buscarlo también a través del precio o la publicidad en la búsqueda constante del éxito financiero.

Las reflexiones anteriores, además de que permiten profundizar en la comprensión y alcances del término mercadológico, han permitido que otros teóricos o investigadores, elaboren aportaciones que enriquezcan no sólo el proceso de comercialización en la práctica, sino que además generen filosofía de negocios que inspiren a quienes se desempeñan, estudian o investigan en estas áreas.

Uno de ellos es Pearson (2014) quien propone la existencia de veinte variables mercadológicas, las cuales, a través de su combinación y desarrollo estratégicos y una coordinada puesta en práctica en el mercado de consumo, no solamente genera orden, visión de conjunto, estructura para la toma de decisiones o inversión en presupuestos, sino que busca crear una plataforma de trabajo bien orientado en beneficio del cliente, el producto, servicio o experiencia y las organizaciones involucradas en dichos procesos. Se sugieren cuatro dimensiones:

a. Principios Básicos: abarca producto, precio, plaza, promoción y empaque.

b. Acciones: planeación, persuasión, relaciones públicas, empujón/tirón y posicionamiento.

c. Mediciones: utilidades, productividad, sociedades, poder y percepción.

d. Conductas: personas, positivismo, profesionalismo, pasión y personalidad.

Para efectos de esta investigación, se emplearán solamente las primeras cinco variables que conforman el apartado de los principios básicos, pues son fundamentales en la génesis del diseño y construcción de una logística de consumo en este caso editorial. 
El Producto es comprendido como la unidad básica del universo mercadológico y el detonante de todo esfuerzo de negocio después de la detección de la necesidad o del deseo y la ingeniería que le dio origen antes de ser colocado en un mercado determinado. De acuerdo con Kotler y Armstrong "la gente satisface sus necesidades y deseos con productos y servicios.

Un producto es cualquier cosa que se puede ofrecer en un mercado para su atención, adquisición, uso o consumo y que podría satisfacer un deseo o una necesidad...el concepto de producto no está limitado a objetos físicos; cualquier cosa que pueda satisfacer una necesidad se puede llamar producto (elementos materiales, servicios, personas, lugares, organizaciones e ideas). Además de los bienes tangibles, los productos incluyen servicios, que son actividades o beneficios que se ofrecen a la venta y que son básicamente intangibles y no tienen como resultado la propiedad de algo" (2013, p. 7).

El Precio como entidad de mercado, es el costo que en moneda circulante o sus similares en un espacio geográfico determinado, deben desembolsar los sujetos para apropiarse temporal o definitivamente de un bien determinado, con el objetivo de satisfacer sus necesidades y/o deseos.

De acuerdo con las afirmaciones de Soriano es "el monto que están dispuestos a pagar los consumidores o usuarios para lograr el uso, posesión o consumo de un producto o servicio específico" (1990, p. 3).

En cuanto a la variable de Plaza, ésta queda comprendida como aquel espacio físico o simbólico - catálogos, archivos PDF para intercambio por sistemas de telefonía móvil o tiendas en línea nacionales e internacionales - en donde se colocan los bienes a disposición de la demanda, para su consumo; de acuerdo con Dvoskin se trata además de "un concepto relacionado con la distribución y generación de oportunidades de compra: es el lugar donde se concreta el intercambio...comprende dos áreas muy definidas.

La primera, como ya se dijo, es el lugar concreto donde se vinculan la oferta y la demanda; la segunda es el proceso necesario para que el producto llegue al lugar de compra: nos referimos a la logística" (2004, p. 28).
La Promoción es entendida y ejercida como aquella certeza de que todos los elementos relacionados con la compra/venta de productos y/o servicios necesita ser difundida, compartida, expresada, comunicada a través de todos los medios existentes o por crearse de acuerdo con la inventiva de mercadólogos y publicistas y acorde a las características de los consumidores o usuarios a quienes van orientados.

De acuerdo con la American Marketing Asociation en Socatelli se trata de "un conjunto de diversas técnicas de comunicación, tales como publicidad, venta personal, promoción de ventas y relaciones públicas, que están disponibles para que un vendedor (empresa $u$ organización) las combine de tal manera que pueda alcanzar sus metas específicas" (2015) y sus principales herramientas son la Publicidad, la Venta Personal, las Relaciones Públicas, la Promoción de Ventas, el Mercadeo Directo, el Merchandising y la Propaganda.

Por último, el Empaque es aquella frontera física que se establece entre el producto y los sujetos, más que como una línea divisoria, una aduana que, a través de la compra y prueba del bien, puede ser franqueada; siguiendo a Miyares en Almaguer esta variable puede ser dimensionada como "todo soporte o continente destinado a contener el producto, facilitar su transportación y presentarlo para la venta...se entiende todo aquel material que guarda y protege al producto, forma parte integral del mismo, de su proceso de planeación como tal y lo distingue de otros artículos" (2001, párr. 1113).

Para efectos de esta investigación, se empleará el modelo teórico de Pearson (2014, P. 12) en su primera categorización de principios básicos, a partir del cual estará orientado no sólo el diseño de la técnica sino el trabajo de análisis e interpretación de los resultados que se obtuvieron durante el trabajo de campo.

\section{Metodología para desarrollar}

El alcance de la investigación fue exploratorio de carácter transeccional, debido a que se estudia un fenómeno comunicativo mercadológico desde una primera aproximación de su comportamiento. 
La herramienta fue realizada en un tiempo determinado y servirá como antesala de conocimiento para las propuestas de indagación con mayor profundidad del binomio consumidor - libro (Hernández, Fernández y Baptista 2014, p. 90). Como objetivo metodológico se planteó recoger información independiente y conjunta que se analizó sin generar correlaciones de datos, en torno a las cinco variables de la mezcla mercadológica que influyen de manera directa en la decisión de comprar de los consumidores literarios de acuerdo con Hernández, Fernández y Baptista (2014, p. 92). El estudio realizado fue no experimental, dado que el sujeto no fue extraído de su cotidianidad para la recolección de datos. La muestra fue probabilística, conformada por 250 individuos, con respecto al total de pobladores de la capital potosina, conformada por 824,229 personas (INEGI, 2015), con un nivel de confianza de $95 \%$ y un intervalo de confiabilidad de 6.2.

Fueron elegidas para el estudio, aquellas personas que hayan ingresado a la sucursal para consultar o comprar materiales literarios en la librería Gandhi, en la sucursal ubicada en avenida Venustiano Carranza \#2301, de la Colonia Las Águilas, establecida en la ciudad de San Luis potosí, S.L.P., debido a que en los resultados obtenidos en un estudio previo, efectuado por los mismos investigadores, acerca del posicionamiento de las librerías que ofertan estos productos dentro de la zona metropolitana de la capital del estado, "Librerías Gandhi" fue la mejor posicionada en el imaginario de los sujetos con un $54.4 \%$ con respecto a su competencia más cercana: "Librería Porrúa" con un $19.9 \%$. Las edades de selección para ser encuestados fueron de entre dieciocho y ochenta y cinco años, con un nivel socioeconómico A/B, $\mathrm{C}+\mathrm{y} \mathrm{C}, \mathrm{y}$ de clase social A, B y C.

La herramienta que se aplicó fue un cuestionario con catorce preguntas cerradas donde cada interrogante contaba con resoluciones que se consideraron para no eliminar o descartar posibles opciones a considerar dentro de las variables de análisis (Gabmara, 2002, en Hernández, Fernández y Baptista Lucio, P. 2014, p. 218) y dos abiertas, que sirvieron para lograr amplitud y profundidad en las decisiones que los encuestados tomaban en su consumo con respecto a las respuestas de las indagatorias cerradas, siguiendo asimismo a Hernández, Fernández y Baptista P. 2014, p. 221).
En los cuales se indagó sobre aquellos detonantes de la mezcla mercadológica que llevan al individuo a decidir sobre el consumo de un texto.

\section{Resultados}

El perfil general de los consumidores de libros con la especificidad puntualizada en la metodología previa, se aglutinan con altos porcentajes entre los 18 y los 50 años de edad y disminuyen dramáticamente a partir de los 51 ; si bien las mujeres consumen más estos productos que los hombres (3\%) ambos géneros lo hacen casi por igual y también se manifestó que conforme avanza la edad se va leyendo menos: en cuanto a su último grado de estudios, adquieren mucho más estos productos aquellos con licenciatura, seguidos por quienes cuentan con un posgrado y enseguida los de bachillerato. El $(82 \%)$ lee un libro cada 6 meses y el $(16 \%)$ uno cada quince días.

De la herramienta aplicada emanan diferentes resultados que son importantes de revisar: el 54\% de los consumidores de 1 a 3 libros mensuales son mujeres. En cuanto al precio, aquellas personas que han concluido una carrera universitaria, esta variable es de suma importancia al momento de determinar si realizan la compra o no (57\%) y especificando en cuanto a la relación entre adquisición y costo, para el $(31 \%)$ de las mujeres que han concluido una maestría o especialidad, el valor de estos productos, no es una limitante para realizar la compra, sin embargo, este factor no es determinante en cuanto a la adquisición de volúmenes, pues solamente hay un $20 \%$ de diferencia entre el grupo que afirma que el dinero invertido puede detener su compra de quien al final la efectúa.

El gusto/hábito/placer por la lectura, es el detonante del consumo con mayor potencial dentro de los compradores puesto que el (45\%) de las personas señalan, que es mediante esta afición que se han acercado a las librerías, seguidos por las recomendaciones que han recibido de uno o varios integrantes de sus grupos de pertenencia/referencia, los cuales son fuentes de credibilidad para aproximarse a determinados títulos $(34 \%)$ y la sinopsis que acompaña a la publicación en la parte posterior o solapas de la misma, influye poderosamente en su decisión de adquirirla. 
Casi la mitad de la muestra acude cada tres meses a la librería objeto de estudio a efectuar una compra y con una diferencia poco relevante $(5 \%)$ lo hace cada treinta días. Muy poco porcentaje de los sujetos abordados eligen libros para regalarlos a alguien y afirmaron que siempre que visitan el espacio de venta, difícilmente lo abandonan sin haber comprado algo.

El (66\%) de los consumidores se inclinan por contenidos históricos, como elemento primordial al momento del proceso de toma de decisiones en cuanto a la adquisición de estos materiales, seguido por el renombre/prestigio que tiene el autor del libro (27.2\%). Cuando la persona evalúa las variables anteriores y las pone en punto de comparación con el precio este deja de ser importante. Al menos entre los individuos objeto de estudio, tanto el diseño editorial como el peso y tamaño de los materiales no son de vital relevancia, pues se manifestaron como los factores menos importantes dentro de aquellas jerarquías que perfilan sus decisiones de compra, ya que el (77.2\%), las colocó en el último lugar junto con la casa productora y la portada del libro.

El $(37 \%)$ prepondera la adquisición cuando el libro tiene pasta gruesa y el (44\%) relaciona el elemento anterior, más un buen diseño de portada, como una combinación que justifica un precio elevado. También es prudente indicar que los consumidores no tienen inconveniente con las diferentes presentaciones del libro para incluirlos en su canasta/bolsa de adquisiciones.

Si bien no son determinantes, a los individuos investigados le agrada en forma significativa dentro de su evaluación del objeto antes de hacer elecciones específicas, interactuar con los materiales editoriales: poder extraerlos de sus envolturas transparentes plásticas que forman parte del empaque, experimentar la textura del papel en que está impreso, verificar el tamaño tipográfico, hojear un poco de los contenidos (76\%) o leer las solapas con sinopsis adicional o datos del escritor (85\%). En cuanto a la ingeniería de producto, la dimensión de la letra empleada es vital para el consumidor, por lo que durante el trabajo de campo, se le facilitó a cada uno de los integrantes de la muestra, una imagen con diferentes tamaños de fuente, para que eligiera aquella que le permite aproximarse mejor al texto.
De esas muestras, aquellas que fueron más señaladas como óptimas para la lectura y que pueden influir mas no determinar la compra fueron 11 puntos $(24 \%)$ y 12 puntos $(27 \%)$; para el $(68 \%)$ el tamaño y número de páginas no representan un impedimento para decidir con respecto a un título, si la historia es interesante y el autor reconocido.

Con respecto a la variable de la promoción el (46\%) considera que los descuentos son un impulso significativo, cuando de alguna manera el precio condiciona o limita la compra. La totalidad de la muestra comparte que leer es una actividad costosa y que si bien los productos editoriales justifican el precio de venta, no descartan ni minimizan la influencia que algunas reducciones en los costos en fechas específicas o de manera aleatoria, incrementaría su nivel de consumo, junto con algún sistema de recompensas por compras, mientras que los meses sin intereses en bancarias participantes o liquidaciones de catálogo no le resultan especialmente atractivas a la población investigada.

Con respecto a la variable plaza, se analizó la sucursal de librerías "Gandhi" ubicada en la avenida Venustiano Carranza, pues en un sondeo realizado por parte de los investigadores de manera previa, fue identificada como la librería más posicionada de la ciudad. El (56\%) de los encuestados identifican positivamente a la ubicación de ésta, pues al encontrarse establecida en una de las arterias más concurridas dentro de la mancha urbana, se encuentra con frecuencia incluida dentro de los trayectos de transporte de los usuarios, además de que cuenta con una amplia plaza de estacionamiento.

Por otra parte, el (44\%) señala que el catálogo de libros con los que cuenta es amplio, diverso y actualizado; al (56\%) le gustaría que contaran con más libros de especialidad académica, pues la mayoría busca esta clase de títulos para el trabajo o para el estudio de posgrado; el diseño interior de los espacios donde se encuentran ubicados los ejemplares, señala el (67\%) como de difícil acceso, pues los libreros o exhibidores se encuentran incluso a nivel de piso y en numerosas ocasiones, los consumidores deben estar inclinándose o hincándose para buscar ciertos títulos, situación que reconocen como incómoda y poco conveniente. 
El (77.2\%) identifica que los precios no son accesibles, pero al identificar a estos bienes como histórica y tradicionalmente caros, están dispuestos y convencidos a desembolsar por lo que consideran un buen título, cantidades superiores a los $\$ 300.00$ pesos. De igual forma el (62\%) señaló que el servicio por parte de los colaboradores de sucursal es excelente, pues brindan asesoría al cliente cuando no conoce la ubicación de los libros, permiten abrir los empaques donde esta resguardado el título, auxilian en cuanto a la ubicación de los materiales y se preocupan por proporcionar una experiencia positiva y satisfactoria a los clientes.

\section{Conclusiones}

El libro por sus características mercadológicas y sociales, al ser un producto cultural que se encuentra dentro de un mercado, tiene que ser tratado desde las herramientas de la comercialización como una propuesta de valor para sus consumidores. De acuerdo con Thomson (2006), se cumplen, dentro del proceso integral de comercialización de libros, las nueve áreas reflexivas que menciona: se trata de un intercambio, social, administrativo, donde interactúan sujetos entre sí con la finalidad de ofertar mercancías con valor de tipo cultural que satisfacen necesidades y deseos de ciertos sectores poblacionales, dentro de un escenario de negocio planificado, organizado, bien implementado, dirigido y controlado; en donde se da cumplimiento a objetivos y metales corporativas tanto de la cadena editorial como de quienes distribuyen estos bienes - los cuales han sido diseñados en función de los diferentes perfiles de consumidores - en sus modalidades físicas y digitales, las cuales permiten una sana capacidad productiva y de consumo que alimenta a los estándares de calidad, desplazamiento de producto o de comunicación para la producción interna/externa - por mencionar solamente algunos elementos organizacionales - de quienes integran la cadena de trabajo editorial en México, al menos en el caso regional que se abordó en la presente investigación.

Al partir de la perspectiva de Pearson (2014) los elementos fundamentales que sustentan la plataforma inicial de negocio de todo producto/servicio - precio, plaza, producto, producto, empaque - están presentes a lo largo de la experiencia completa de comercialización de productos culturales impresos en el formato abordado en esta investigación, sin excepción.
El libro como complejo e integral constructo mercadológico, en su ejercicio de consumo, conserva la lógica de las categorías básicas, en una definida estructura pentavalente y que lo caracteriza en lo particular y en conjunto tanto como un bien perfilado y un diferenciador sustancial para quien opta por consumirlo.

La variable producto incluye integradores tales como las características generales y específicas del papel empleado en interiores y exteriores, la presencia/ausencia de plastificado en portadas/contraportadas o encuadernación rústica o pasta dura, así como fotografías o ilustraciones a color/blanco y negro, el tamaño de la edición, la calidad descriptiva de la sinopsis, la historia a contarse, el autor sea éste reconocido o no, además del número de páginas, el tamaño y estilo tipográfico, el diseño editorial, imágenes del(os) autor(es) o de recomendaciones de otras publicaciones del sello editorial, cintillos o fajas removibles a lo largo del cuerpo para efectos promocionales, ocasionalmente separadores para lectura y envoltura transparente plástica.

Los consumidores resultan ser altamente sensibles a todas estas especificaciones de la ingeniería del producto, pues no sólo estimulan o inhiben la decisión de compra, sino que, a juicio de ellos, configuran la constelación de placeres asociados a la lectura y a la adquisición de estos materiales, funcionando siempre en sinergia, pues en la evaluación del comprador en cuanto a costo/beneficio, está siempre relacionada con la siguiente categoría, que si bien no resulta significativamente determinante, si posee su relevancia en el análisis previo a la compra.

El precio como entidad mercadológica, si bien representa para los consumidores más tiempo para decidirse en adquirir un libro, no es un obstáculo de peso, pues contrapone inmediatamente todos los puntos del producto que se explicitaron anteriormente, con el costo que habrá de cubrirse. Una adecuada mezcla estratégica de estas dos variables incrementa con poderosamente las posibilidades de venta, además de que estos bienes de consumo guardan un posicionamiento - cierto o falso - de artículos suntuarios entre quienes los buscan en cualquier espacio donde se vendan, lo que flexibiliza los criterios del individuo cuando los paga. 
Respecto a la plaza la población objeto de estudio, al igual que en el caso del rubro producto, manifiesta altos estándares en materia del espacio involucrado en la compra/venta de estos bienes; si bien el servicio a clientes es otra dimensión de la Mercadotecnia, los sujetos la relacionan en forma directa, al menos en este estudio, con la plaza. Consumidores atentos a la iluminación adecuada, la ventilación natural o al aire acondicionado, a la música de fondo y la altura de los exhibidores con la consecuente facilidad de uso y aproximación, las secciones en que están organizados los volúmenes; la accesibilidad, presencia, eficiencia, eficacia, amabilidad, experiencia y conocimiento de los vendedores; la diversidad de formatos para pagos, la existencia de un sistema de apartado, el estacionamiento gratuito, la higiene y orden del lugar.

Aunque estos elementos no revistieron especial relevancia durante el proceso de toma de decisiones para la compra de libros, curiosamente son considerados como una especie de condición obligada, estrechamente asociada, esperada, vinculada a lo que ellos aprecian cuando adquieren estos materiales. No hubo menciones acerca de su preferencia/indiferencia relacionada con otros servicios o mercancías como artículos promocionales, cursos, conferencias y talleres, lecturas para niños o presentaciones de libros.

La promoción y sus diversas aplicaciones no constituyen una categoría que guarde estrecha relación con la adquisición de libros, al menos en este estudio de caso: si bien muestran agrado hacia descuentos, puntos premia o estrategias similares, éstas no tienen peso al momento de elegir, decidir o pagar sus compras y este fenómeno puede tener su origen en todas las reflexiones que se han hecho previamente en relación con el elemento precio.

Finalmente, en lo tocante al factor empaque, los consumidores se manifestaron en contra de él (envoltura plástica transparente) porque les impide interactuar con los materiales en cuanto a las características que se abordaron en el párrafo relacionado con el producto. Sin embargo, una vez que eligen comprarlo, devuelven el volumen abierto y toman un libro sin desenvolver para llevarlo con ellos: es decir, estorba para decidir, pero sirve para proteger.
Dentro de esta categoría podrían incluirse las bolsas plásticas, de compra, impresas con frases promocionales que obsequia la librería a sus clientes, pero éstas no fueron mencionadas en el estudio por parte de los individuos, pero cabe mencionar que de varios meses a la fecha de realización de la investigación y según el personal de este negocio, las personas prefieren no utilizarlas y llevar su compra en la mano como una actitud ecológica.

\section{Referencias.}

Almaguer, E. (2001, 14 de junio). Envase, empaque y embalaje de productos. Gestiopolis. Recuperado el 27 de agosto de 2019 de: https://www.gestiopolis.com/envase-empaquey-embalaje-de-productos/

American Marketing Asociation, en MarketingPower.com, sección Dictionary of Marketing Terms, URL del sitio: y posteriormente traducida al español. (Fecha de consulta 16 de junio de 2015).

Cardozo, S. (2007). La comunicación en el marketing. [Versión electrónica]. Visión General, 6(2). 196-206.

Cortez, M. (2016, 7 de diciembre). Historia de la mercadotecnia [en línea]. Merca2.0. Recuperado el 27 de agosto de 2019 de: https://www.merca20.com/historia-lamercadotecnia/

Dvoskin, R. (2004). Fundamentos de marketing: teoría y experiencia. Buenos Aires, Argentina, Ediciones Granica S.A.

García, J. (2014). Neuromarketing: cuando el doctor Jekyll descubrió a Mr. Hyde. Madrid, España, Editorial RA-MA HYDE.

Instituto Nacional de Estadística, Geografía e (2015). Censo Nacional de Población. Recuperado el 17 de julio de 2019 de: $\mathrm{http} / / /$ cuentame.inegi.org.mx/monografias/infor macion/slp/poblacion/

Kotler, F. y Armstrong, G. (2003). Fundamentos de Marketing. México, Pearson Educación.

Kotler, F. y Armstrong, G. (2013). Fundamentos de Marketing. México, Pearson Educación 
Pearson, D. (2014). Las 20 P's del Marketing. México, Grupo Editorial Patria.

Ries, A. y Trout, J. (2006). La guerra del marketing. México, Mc Graw-Hill Interamericano.

Santesmases, M., Sánchez, A. y Valderrey, F. (2014). Fundamentos de mercadotecnia. México, DF, Grupo Editorial Patria.

Santesmases, M., Sánchez, J., Pintado, T. y Merino, María. (2013). Fundamentos de marketing. México, Editorial Pirámide.

Soriano, C. (1990). Marketing mix: conceptos, estrategias y aplicaciones. Madrid, España, Ediciones Diaz de Santos, S. A.

Stanton, W., Etzel, M. y Walker, B. (2004). Fundamentos de marketing. México, Mc GrawHill Interamericana.

Thompson, I. (2006). Definición de Marketing. Recuperado el 27 de agosto de 2019 de: https://es.scribd.com/document/310779981/Iva n-Thompson

Van Riel, C. (2003). Nuevas formas de la comunicación organizacional [Versión electrónica]. Razón y Palabra, 34. Recuperado el 27 de agosto de 2019 de: http://www.razonypalabra.org.mx/anteriores/n3 4/cvanriel.html 